\title{
Diacronie
}

Studi di Storia Contemporanea

$N^{\circ} 22,2$ | 2015

Costruire

\section{Xavier Daumalin, Le patronat marseillais et la deuxième industrialisation: 1880-1930}

Jacopo Bassi

\section{OpenEdition}

\section{Edizione digitale}

URL: http://journals.openedition.org/diacronie/2168

DOI: 10.4000/diacronie. 2168

ISSN: 2038-0925

\section{Editore}

Association culturelle Diacronie

\section{Notizia bibliografica digitale}

Jacopo Bassi, «Xavier Daumalin, Le patronat marseillais et la deuxième industrialisation: 1880-1930 », Diacronie [Online], № 22, 2 | 2015, online dal 01 juin 2015, consultato il 12 octobre 2020. URL : http:// journals.openedition.org/diacronie/2168; DOI : https://doi.org/10.4000/diacronie.2168

Questo documento è stato generato automaticamente il 12 octobre 2020

Creative Commons License 


\section{Xavier Daumalin, Le patronat} marseillais et la deuxième industrialisation: 1880-1930

Jacopo Bassi

NOTIZIA

Xavier Daumalin, Le patronat marseillais et la deuxième industrialisation: 1880-1930, Aix-enProvence, Presses universitaires de Provence, 2014, 326 pp. 
1 Il libro di Xavier Daumalin rappresenta la prosecuzione di un lavoro di ricerca già avviato da molti anni sulle origini e le specificità dell'industrializzazione marsigliese. Nella sua analisi l'autore privilegia quattro aspetti, interdipendenti fra loro: gli investimenti economici, l'innovazione tecnologica, i mercati e il contesto sociale.

2 Se il primo elemento permette di comprendere la struttura, il funzionamento dell'impresa marsigliese e i cambiamenti avvenuti nel periodo preso in esame, il secondo - quello dell'innovazione tecnologica - consente di indagare la nascita di nuovi comparti produttivi. Il tema dei mercati è invece strettamente legato al ruolo del porto marsigliese, anche e soprattutto in relazione al mondo coloniale francese. Infine il contesto sociale offre un'interessante indagine sociologica oltreché storica, sull'immigrazione - italiana, ma non solo - a Marsiglia.

L'approccio locale si dimostra un efficace sistema per indagare un'area industriale con le sue peculiarità; Daumalin, inoltre, mette a disposizione del lettore un quadro sempre chiaro ed esaustivo delle fonti e della loro provenienza, incoraggiando ulteriori ricerche sul tema.

\section{AUTORI}

\section{JACOPO BASSI}

Ha conseguito la Laurea Triennale in «Storia del mondo contemporaneo» presso l'Università di Bologna sostenendo una tesi in Storia e istituzioni della Chiesa ortodossa dal titolo Tra Costantinopoli e Atene: Il passaggio delle diocesi dell'Epiro all'amministrazione della Chiesa di Grecia e la 'Praxis' del 1928; presso lo stesso ateneo, nel 2008, ha discusso la tesi specialistica in Storia della Chiesa dal titolo Epiro crocifisso o liberato? La Chiesa ortodossa in Epiro e in Albania meridionale nel XX secolo (1912-1967). Attualmente collabora con le case editrici Il Mulino e Zanichelli. 